\title{
HAIL DAMAGE IN FOREST STANDS ${ }^{1}$
}

\author{
BY C. G. RILEY 2
}

\author{
CLIFFORD GEORGE RILEY
}

Raised on a farm in Muskoka, Ontario; obtained B.S.A., Ontario Agricultural College, 1923; M.F. at Yale School of Forestry, 1928; Ph. D. at University of Toronto, 1946. Since 1930 employed in research in forest patbology, Division of Botany and Plant Pathology, and Division of Forest Biology, Department of Agriculture, Ottawa. Responsible for establishing new Laboratory of Forest Pathology serving the three Praivie Provinces, but now excluding Alberta, in 1948. He is presently Officer-in-Charge.

\section{ABSTRACT}

Hail occasionally causes severe damage in forest stands. Near Candle Lake, Saskatchewan, a severe bail storm damaged 70- to 80-year stands including mixed white spruce (Picea glauca (Moench) Voss), aspen (Populus tremuloides Michx.), and jack pine (Pinus banksiana Lamb.); and pure jack pine. Characteristic symptoms seven years after the initial occurrence included: dead trees, particularly jack pine; dead tops; crowns partly dead and conspictuously thin on the side that faced the storm; open and bealed wounds all on the same side of the trees, especially on the thin-barked upper parts, all traceable to the annual ring of the same year.

Damage caused by hail in forest stands is perhaps much more common than is generally realized. By comparison, reports of hail damage in agricultural crops are of common occurrence. Two main reasons probably account for the rarity of reported hail injury in the forest. The relatively small areas commonly affected by severe hail may go unobserved in the large stretches of little-travelled forest, whereas similar areas in agricultural land would certainly not pass unnoticed. Also, trees generally are better able to withstand the bombardment of hail than are farm crops. Unusually heavy hail storms, however, are capable of causing severe damage to trees. Rarely a summer passes that we do not read in the news of hailstones as large as pigeon's eggs, golf balls, or even oranges. It is not surprising that missiles capable of wrecking roofs, breaking automobile windshields, and causing many other comparable kinds of destruction are also capable of pounding bark off trees and breaking branches.

The characteristic symptoms of hail injury in forest stands are among the simplest to diagnose, and yet this form of "disease" a few years after its initial occurrence is one of the most likely to puzzle woodsmen.

To understand the effect, it is only necessary to consider for a moment the nature of the cause. Hailstones can only strike downward and in the direction of the wind. Therefore, the bruising effect occurs only on one side of the

\footnotetext{
1 Contribution No. 98 from the Division of Forest Biology, Science Service, Department of Agriculture, Ottawa, Canada.

2 Officer-in-Charge, Laboratory of Forest Pathology, Saskatoon, Sask.
} 
tree and the upper and windward side of branches. Upper branches and those on the windward side of the crowns tend to shield those below and on the sheltered side, and the latter therefore usually escape severe injury. One of the most positive symptoms is that all species of trees in the stand, coniferous and broad-leaved alike, are similarly affected, a distinction which is shared only with other physiological diseases such as fire and frost damage. Most diseases caused by fungi and insects are characterized by attacking only certain kinds of trees in the stand and not directly affecting others.

Following is a description of hail damage seven years after its initial occurrence in the Candle Lake Provincial Forest, approximately 45 direct miles northeast of Prince Albert, Saskatchewan. The affected stands were in the 70-to-80-year age class, and included mixed white spruce (Picea glauca (Moench) Voss), aspen (Populus tremuloides Michx.), and jack pine (Pinus banksiana Lamb.); and pure jack pine.

The conspicuous features of the stand when viewed in a northeasterly direction were the dead tops and one-sided crowns of all trees in the main crown class, with the bare sides all facing northwest, the direction from which the hail had struck (Fig. 1, 2, 3). A most striking feature of the damaged aspens was the numerous black callused bruises on the smooth, nearly white bark, suggesting pock marks, and always on the same side of the tree (Fig. $3,4)$. Looking southwest, only "pock-dotted" bark could be seen on the aspens, while from the opposite direction the stems appear normally smooth and clean. In the jack pine stand so many of the trees had died as a result of the injury that a dense growth of brush and other ground vegetation had sprung up, and the area looked much as if it had been burned (Fig. 2), except that there was no charring. The width of the damaged area was only about four or five chains, but it extended a considerable undetermined distance in the direction followed by the storm. This is characteristic.

On a typical dominant white spruce which was felled and examined closely, characteristic symptoms were as follows. The wounding was most severe on the

EFFECTS OF HAIL INJURY SEVEN YEARS AFTER ITS INITIAL OCCURRENCE

\section{PLATE I}

Fig. 1, 2, 3. White spruce, jack pine, and aspen, respectively. Note one-sided crowns, and die-back of tops and branches on exposed side. Many jack pines entirely killed.

Fig. 3, 4. Scars on aspen bark caused by bruising.

\section{PLATE II}

Fig. 5. Scars on stem of white spruce.

Section through a scar on stem of white spruce. This was not an open wound, which gave rise to irregular sub gequent growth. These overgrown wounds will remain as local internal defects in the tree, all originating at the same growth ring.

Fig. 7, 8, 9. Typical condition of main stems within the crowns of jack pine, white spruce, and aspen, respectively. The bark of the jack pine was completely torn away, half-way around the stem. The exposed wood is dry and checked. The opposite side is still growing. The wound on spruce is being overgrown by a trick roll of living callus. The living aspen bark shows typical "pock" marks caused by bruising.

Fig.10, 11. Branches of white spruce and jack pine, respectively. Note the healed and Photography in part by P. J. Kristapovich and J. E. Patterson. 


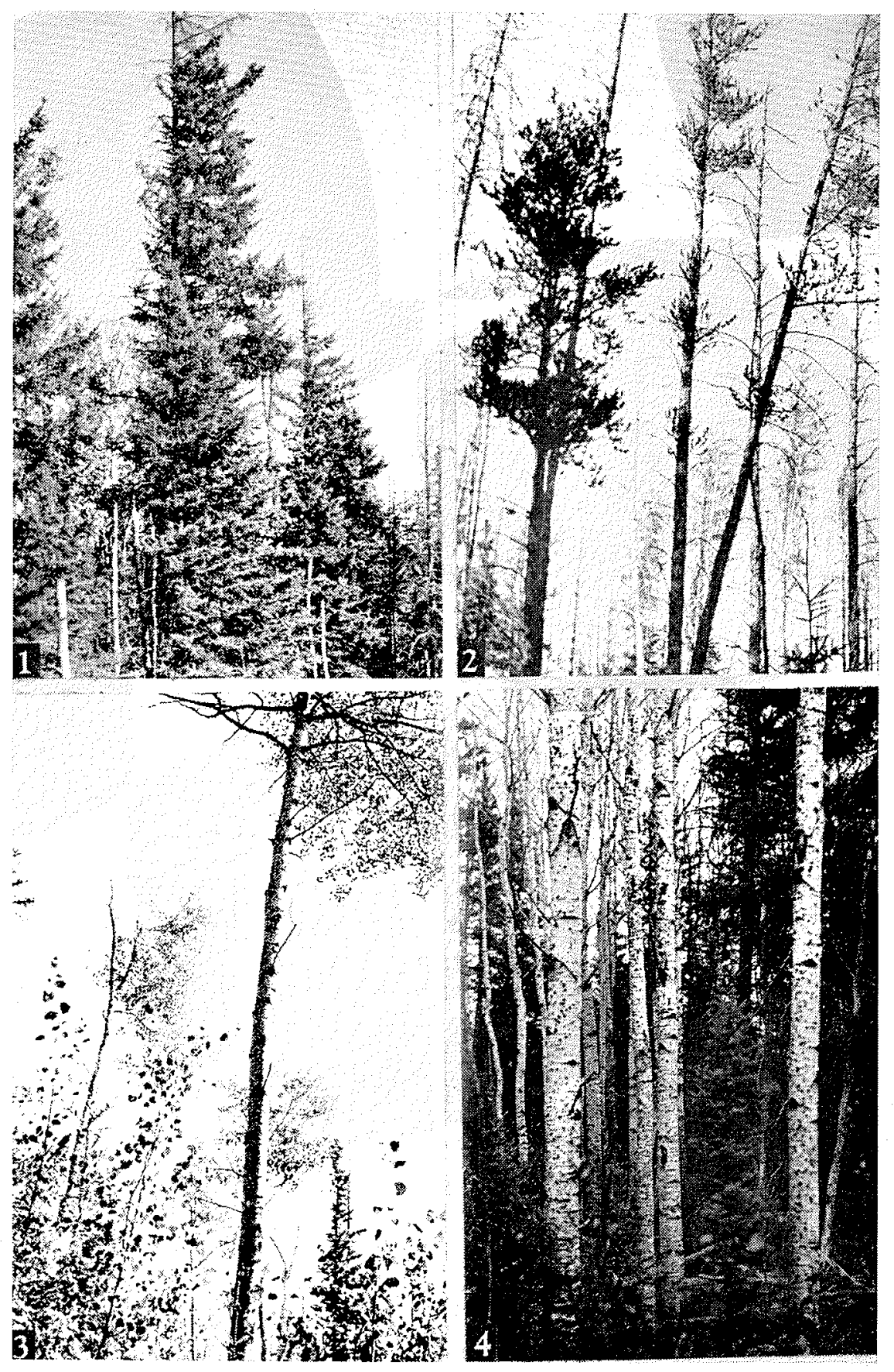



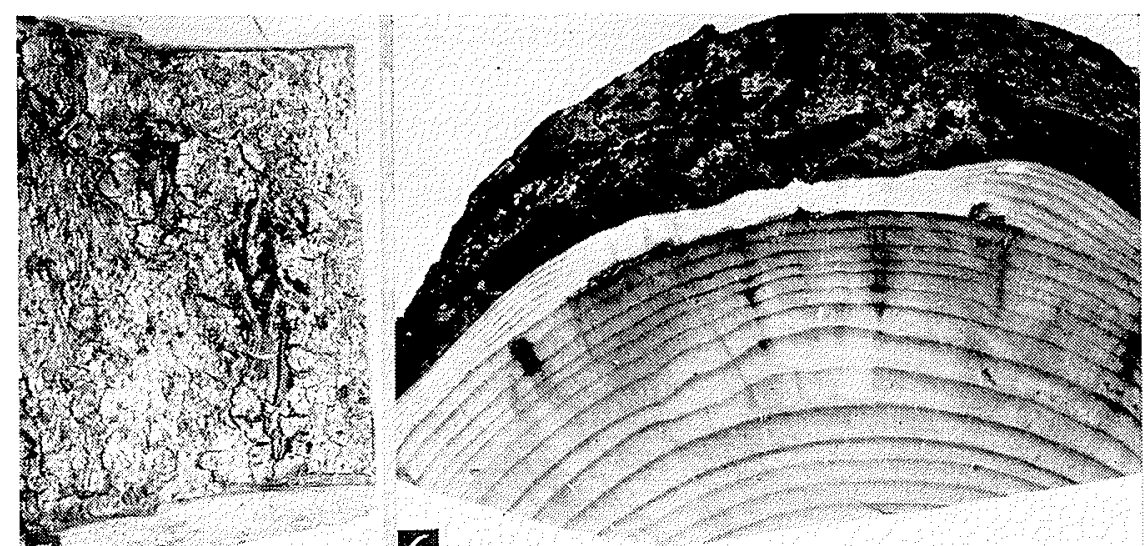

5
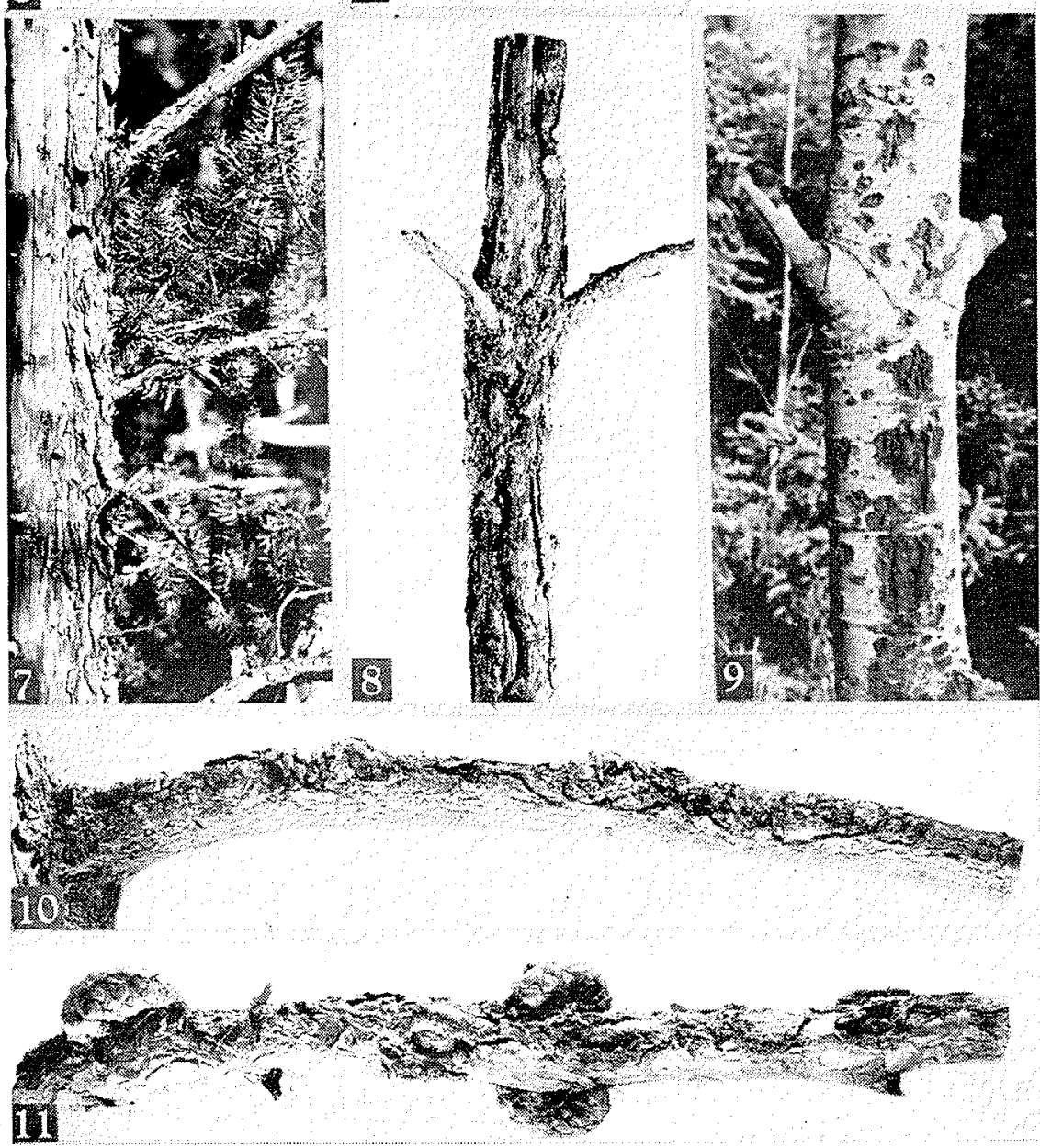
thin-barked upper part of the tree. On the exposed side of the main stem, from the tip down to a diameter of about 3 inches, patches of bark had been completely pounded off, leaving open wounds. The top was dead for several feet down from the tip. Below this the wounds were in all stages of healing, with "rolls" of callus at the margins (Fig. 8). Many small wounds were completely healed, leaving conspicuous scars. Still farther down the stem, where the hail stones had failed to break completely through the thicker bark, were numerous elongated scars one to three inches in length, which indicated severe bruising (Fig. 5). Beneath each scar was a pitch pöcket in the wood, invariably overgrown by the same number of annual rings (Fig. 6). This is an important diagnostic character. The growth rings indicated that the hail storm had occurred seven years previously. Difficulty in distinguishing between true annual rings and false annual rings which commonly are associated with interruption of growth by injuries, sometimes makes exact determination of age of wounds uncertain. On the branches the wounds were all on the upper side and the side facing the direction of the storm (Fig. 10 and 11$)$.

In the damaged jack pine stand the symptoms were generally similar to those in the spruce except that greater areas of bark had been completely stripped off the upper stems, and there was less evidence of healing (Fig. 7).

The wounds were most conspicuous on aspen, on the smooth bark of which a relatively harmless abrasion characteristically gives rise to a black rough callus which is conspicuous on the smooth whitish stem (Fig. 3, 4, 9).

In the damage area described above, the most serious die-back and mortality as a result of the hail undoubtedly was caused by the drying of sapwood, which followed the loss and breaking of the bark. Other secondary injury arose from the attacks of insects and fungi which were favored by the wounds and the partial drying of the wood.

In spruce, the effects of the one-sided reduction of crown and wounding of stem were strikingly evident in the growth-ring pattern throughout the length of the stem. The annual rings which were formed prior to the date of injury were regular and quite broad. Subsequent rings were extremely narrow on the injured side of the tree, even in the thick-barked lower part of the stem where wounding was negligible, while on the opposite side of the stem the regularity of growth had been interrupted by only two narrow rings coinciding with the year of injury. Growth rings were not examined in the lower part of the stem of jack pine and poplar.

Other instances of hail injury to trees have been examined in Saskatchewan and Alberta. The damage done at Candle Lake is the severest that has been observed by the writer. 